\title{
Septicaemic shock \\ Report of three cases: a review of diagnosis and management
}

\author{
Gillian C. Hanson \\ M.B., M.R.C.P.
}

Intensive Therapy Unit, Whipps Cross Hospital

OVFR the last 2 years twenty patients with septicaemic shock, proven by positive blood cultures, have been admitted to the Unit. Another twenty patients with negative blood cultures, and where septicaemia was thought to be a major factor producing hypotension, were admitted during this period. These patients had received antibiotics before the blood cultures were taken.

This article is a summary of our experiencewith particular emphasis on the management of septicaemia.

\section{Case histories}

Case 1

Female patient aged 71 years admitted toxic and ill with a vague history of rigors. She had suffered from nausea and slight aching in the right hypochondrium for $3 / 52$ prior to admission. She had no urinary tract symptoms. On examination she was toxic, drowsy with a pulse rate of $140 / \mathrm{min}$, blood pressure $90 / 50$. A mass was palpable in the right hypochondrium which was tender and thought to be a gallbladder. Over the next $24 \mathrm{hr}$ she had several rigors, and her level of consciousness slowly deteriorated. She was transferred to the Unit where a central venous pressure line was inserted, the cvp was found to be normal. Intravenous ampicillin and cephalothin was commenced.

Two hours later her general condition had improved, she was mentally alert and the blood pressure was satisfactory. She was transferred to theatre for laparotomy. At laparotomy the mass was found to be a distended and infected right kidney, the ureter was inflamed and appeared to be blocked due to extensive inflammation and inspissation with pus. The pelvis and ureter were drained. The patient received mannitol post-operatively. Post-operatively the patient became oliguric and remained hypotensive for $24 \mathrm{hr}$. Her condition then steadily improved. Blood cultures grew coliforms sensitive to ampicillin and cephalothin. The pus from the renal pelvis grew

Correspondence: Dr Gillian C. Hanson, Consultant Physician, Whipps Cross Hospital, Leytonstone, London, E.11. the same coliform organisms with similar sensitivities. The patient was treated with cephalothin and am- 3 picillin intravenously for 1 week and was then cr changed to a course of oral septrin. The ureteric or drain was removed after 5 days and subsequent $X-\infty$ rays showed no abnormality in the ureter. She was $\tilde{N}^{\circ}$ discharged well 1 month after admission and $\infty$ subsequent progress was uneventful.

\section{Comments}

This case history emphasizes the importance of efficient pre-operative preparation and correct tim- $\vec{\theta}$ ing for the operative procedure. A right rens $\perp$ mass may on occasions be mistaken for an enlarget gallbladder. Both cholecystitis and acute pyelorie phritis may be associated with rigors, backache and pain in the right hypochondrium. Severe pyelonephritis may on occasions be associated with ureteric $\stackrel{\varnothing}{\varnothing}$ obstruction. Patients with septicaemia secondary to renal infection are very susceptible to acute renal $\overrightarrow{\widehat{O}}$ failure. Should these patients require an operation, post-operative mannitol is an essential part of their management.

\section{Case 2}

Patient aged 19 years was admitted to the Accident Centre following an illegal abortion. At the time of admission the uterus was enlarged to 24 weeks, and was contracting strongly. On vaginal examination, $O$ the external os was open and the membranes bulging.

Within $30 \mathrm{~min}$ the patient spontaneously aborted $\frac{7}{0}$ - the placenta, membranes and foetus being evacuated together. The placenta was thought to be $N$ intact. The patient was noted at this time to be pale, N sweaty and breathless. There was little uterine bleed- N్ ing. She was given ergometrine $0.5 \mathrm{mg}$ intramuscu-
larly.

Five hours later the blood pressure was noted to be low $80 / 60 \mathrm{mmHg}$, pulse rate $120 / \mathrm{min}$. There was no evidence of excessive blood loss. Blood cultures $\overrightarrow{0}$ were taken, intravenous hydrocortisone was given and $500 \mathrm{ml}$ of Dextran 70 followed by $1500 \mathrm{ml} \underset{\mathbb{D}}{\mathbb{Q}}$ plasma was infused over the next $3 \mathrm{hr}$. Nine hours after admission her blood pressure had risen to 


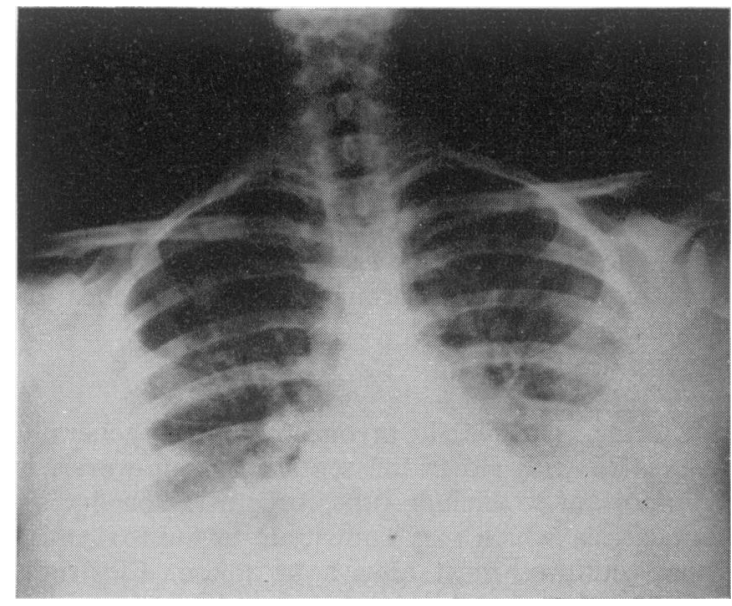

FIG. 1. Amniotic fluid embolism following septic abortion.

110/70 but her tachycardia persisted-she became increasingly breathless and more cyanosed.

Chest X-ray (Fig. 1) showed diffuse patchy infiltration of both bases. In view of the hypotension and persistent tachycardia, it was considered that the patient was most probably suffering from septicaemic shock. The chest X-ray was consistent with amniotic fluid embolism.

Intravenous ampicillin and cephaloridine were given in a dosage of $1.0 \mathrm{~g}$ intravenously 6-hourly, with intravenous hydrocortisone $500 \mathrm{mg}$ 6-hourly for $24 \mathrm{hr}$.

Twenty-four hours after admission her general conditioned improved-she was still orthopnoeic but less cyanosed. The urine output had been good.

Thirty-six hours after admission the patient was less dyspnoeic and there was evidence of clearing on the chest X-ray. Temperature was normal. Blood cultures grew coliform organisms sensitive to ampicillin and cephaloridine.

Forty-eight hours after admission an examination under anaesthetic was performed; some retained products were removed from the fundus and posterior wall of the uterus. Curettings grew coliforms with similar sensitivities to the blood cultures.

Post-operative progress was uneventful. The cephaloridine was changed after $48 \mathrm{hr}$ to cephalothin $1.0 \mathrm{~g}$ intramuscularly 4-hourly, and the ampicillin was continued in the same dose as previously.

Five days later the patient's condition had improved; she was no longer dyspnoeic or cyanosed and the blood cultures were negative.

Nine days after admission she was afebrile. Antibiotics were continued for a further 7 days as oral cephalexin and intramuscular ampicillin.

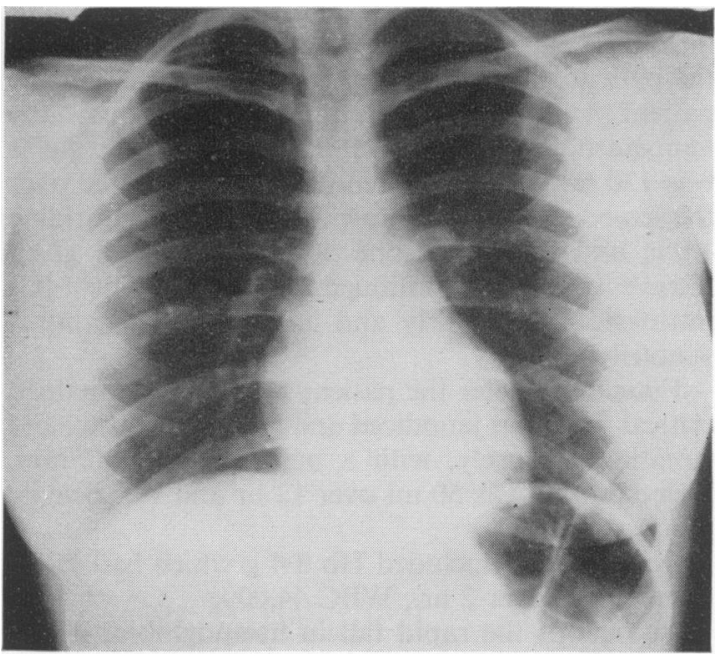

Fig. 2. Chest X-ray 3 weeks after the incident showing clearance of the lung fields.

On discharge the chest X-ray was clear (Fig. 2). One month following discharge, the patient felt well; vaginal examination was normal.

\section{Comments}

This case history is of considerable interest, since the hypotension and hyperventilation could have been attributed to amniotic embolism alone. The patient collapsed immediately after abortion and at this time she was noted to be breathless-a chest Xray taken $9 \mathrm{hr}$ after admission was consistent with microembolism. There was no history of pulmonary aspiration.

It is essential to take blood cultures whenever a septic abortion is suspected-a positive culture gives a positive guide for antibiotic therapy. This patient did not develop any evidence of coagulation failure.

\section{Case 3}

Female 34 years was admitted as an emergency with a 7-week history of amenorrhoea. Over the previous $24 \mathrm{hr}$ she had bled from the vagina and had suffered several hours of sweating and shivering. She denied an attempted abortion at the time

On examination she was shivering and obviously in pain. Temperature $39^{\circ} \mathrm{C}$. Blood pressure $110 / 70$ $\mathrm{mmHg}$, pulse $70 / \mathrm{min}$. Nothing abnormal was found in the cardiovascular or respiratory systems. On examination of the abdomen, a tender mass was palpable rising out of the pelvis, tenderness was also present in both iliac fossae. Vaginal examination revealed the os closed and the uterus enlarged to the size of a 16-18 week pregnancy. 
The diagnosis of septic abortion was made and intramuscular ampicillin prescribed. Six hours later the patient suddenly collapsed. On examination the patient was hyperventilating and anxious; the temperature was $39.2^{\circ} \mathrm{C}$, B.P. $80 / 60$, and the pulse was $120 \mathrm{~min}$. Rebound tenderness was elicited over the lower abdomen. Ampicillin $1.0 \mathrm{~g}$, cephaloridine $1.0 \mathrm{~g}$, and hydrocortisone $500 \mathrm{mg}$ were all given intravenously and continued as cephaloridine $1.0 \mathrm{~g}$ intravenously 8-hourly and ampicillin $1.0 \mathrm{~g}$ intravenously 4-hourly.

Four hours later the patient's condition remained critical-she was jaundiced and hyperventilating and sweating profusely, with a pulse rate of $140 / \mathrm{min}$. Urine output was $50 \mathrm{ml}$ over $12 \mathrm{hr}$ and was heavily blood stained.

Investigations included $\mathrm{Hb} 8.4 \mathrm{~g}$ which had fallen from $10.0 \mathrm{~g}$ over $2 \mathrm{hr}$., WBC 44,000.

In view of the rapid fall in haemoglobin, it was thought the patient had haemolysed; most probably secondary to a Clostridium welchii septicaemia.

At operation the uterus was evacuated manually and foul smelling retained products were removed with ovum forceps.

Culture of the retained products grew a mixed growth of Clostridium welchii and klebsiella organisms. Clostridium welchii sensitive to penicillin; klebsiella sensitive to cephalosporins.

In view of the oliguria and rising blood urea, a peritoneal dialyzing catheter was inserted at the end of the operation.

The patient was given a course of hyperbaric oxygen $\left(1-1 \frac{1}{2} \mathrm{hr}\right.$ at 2.5 atmospheres absolute). The metabolic status was maintained satisfactorily on peritoneal dialysis. She was given a total of $9 \mathrm{hr}$ hyperbaric oxygen over 3 days. Her condition improved until $36 \mathrm{hr}$ after admission when she again became restless, anxious and tachypnoeic. At this time her temperature rose from $38^{\circ} \mathrm{C}$ to $39.8^{\circ} \mathrm{C}$ and her pulse rate increased from 100 to $140 / \mathrm{min}$.

Blood cultures grew Clostridium welchii and klebsiella organisms. The klebsiella were sensitive to cephalosporins, gentamycin, tetracycline and streptomycin-resistant to ampicillin.

It was thought that the most probable cause for her deterioration was Klebsiella septicaemia, since there had been no evidence of further haemolysis following hyperbaric oxygen therapy. Previous experience has shown that Clostridium welchii uterine infections rapidly respond to hyperbaric oxygen and penicillin therapy coupled with adequate surgical drainage.

In view of the renal failure, the cephaloridine was changed to cephalothin $1.0 \mathrm{~g}$ intravenously 4hourly, coupled with intramuscular gentamycinthe dosage being adjusted according to serial blood levels. Septrin was started orally $10 \mathrm{ml}$ (adult suspension $80 \mathrm{mg}$ trimethoprin, $400 \mathrm{mg}$ sulphameth- oxazole $/ 5 \mathrm{ml}$ ) orally 6-hourly for 4 doses, then $8-\frac{2}{\mathbb{Q}}$ hourly.

The patient's condition steadily improveddialysis was continued intermittently for 21 days. Intravenous cephalothin and intramuscular gentamy- $\bar{C}$ mycin were given for 14 days and then treatment $\frac{\bar{\sigma}}{\bar{\sigma}}$. was continued with oral septrin.

At the time of discharge the patient was well, $\stackrel{\widehat{D}}{\stackrel{2}{2}}$ vaginal examination normal, and no evidence of residual sepsis.

\section{Comments}

Uterine clostridial myonecrosis is generally associated with clostridial septicaemia; however, it: is important to exclude other organisms producing 3 . septicaemia which may contribute to the toxaemia. ज Blood cultures must always be taken. Clostridia 0 are rarely found in the blood stream except in uterine $e_{\omega}^{\infty}$ gas gangrene. Haemolysis may occur in coliformin septicaemia but this is rare. Haemolysis in the $\infty$ presence of infection should be ascribed to severe ? clostridial infection until proven otherwise.

The clostridial infection did not cause great 3 concern-Klebsiella septicaemia has a poor prognosis and the deterioration of the patient $36 \mathrm{hr}$ later was $\overrightarrow{0}$ thought to be due to this organism. The Klebsiepa is difficult to eradicate, is generally resistant ampicillin, and is often resistant to cephalosporifo

In view of the patient's critical condition, high doses of gentamycin were given in the first $24 \mathrm{hr}$. It is probable that the high peak blood levels obtained $\stackrel{\circ}{\mathbb{Q}}$ 24 and $48 \mathrm{hr}$ after starting treatment might have been a factor in prolonging the duration of renal failure. $\overrightarrow{0}$

The diuretic phase did not start until 23 days after the onset of oliguria.

\section{Discussion}

The incidence of septicaemia has varied from $1.5 \frac{\text {. }}{9}$. patients per thousand admissions (personal series) to 3 thirty patients per thousand admissions (Fin land, 1970). Finland (1970) showed that the incidence of staphylococcal septicaemia has decreased from $27 \%$ in 1961 to $15 \%$ in 1965 and the incidence of gram negative bacilli and enterococci has increased from $40-50 \%$ over the same period.

The mortality from septicaemic shock has been variously reported as from 36-82\% (Murdoch Speirs and Pullen, 1968), 66\% (Neeley et al., 1970) and $52 \%$ (personal series). The mortality from $\omega$ non-shocked septicaemic patients is approximately half that of the shocked patients.

Septic abortion is one of the leading causes of maternal death in the United States (Bernardo? Santamarin and Smith, 1970). Many authors repor 5 that $50 \%$ of women in septic shock from septico abortion will die (Morris, 1967).

Certain situations are known to predispose the 
TABle 1. Differential diagnosis of septic shock

\begin{tabular}{|c|c|}
\hline Early signs & Alternative diagnosis \\
\hline $\begin{array}{l}\text { Pyrexia (occasionally absent) } \\
\text { Sweating } \\
\text { Restlessness } \\
\text { Some confusion } \\
\text { Tachypnoea } \\
\text { Tachycardia } 90-110 / \mathrm{min} \\
\text { Slight fall in B.P. } 80-100 \mathrm{mmHg} \\
\text { systolic pressure } \\
\text { Mild jaundice } \\
\text { Deterioration during anaesthesia or } \\
\text { failure to regain consciousness after an } \\
\text { anaesthetic }\end{array}$ & $\begin{array}{l}\text { Myocardial failure } \\
\text { Pulmonary embolism } \\
\text { Amniotic fluid embolism } \\
\text { Adverse drug reaction } \\
\text { Incompatible blood transfusion } \\
\text { Transfusion of old blood } \\
\text { Blood volume loss in the absence of } \\
\text { septicaemia }\end{array}$ \\
\hline \multicolumn{2}{|l|}{ Late signs } \\
\hline $\begin{array}{l}\text { Coma } \\
\text { Tachypnoea often associated with cen- } \\
\text { tral cyanosis }\end{array}$ & $\begin{array}{l}\text { Cerebral catastrophe } \\
\text { Myocardial failure }\end{array}$ \\
\hline $\begin{array}{l}\text { Cold pale extremities with peripheral } \\
\text { cyanosis }\end{array}$ & Pulmonary $\left\{\begin{array}{l}\text { aspiration } \\
\text { thrombotic embolism } \\
\text { amniotic fluid embolism }\end{array}\right.$ \\
\hline $\begin{array}{l}\text { Skin cold and clammy } \\
\text { Tachycardia }>110 / \mathrm{min} \\
\text { Hypotension }<80 \mathrm{mmHg} \\
\text { Moderate jaundice } \\
\text { Oliguria } \\
\text { Coagulation abnormalities }\end{array}$ & $\begin{array}{l}\text { Hepatocellular failure } \\
\text { Blood volume loss in the absence of } \\
\text { septicaemia }\end{array}$ \\
\hline
\end{tabular}

patient to septicaemia. In surgical practice, operations on the biliary and urinary tract in the presence of infection may lead to septicaemia. Laparotomy for peritonitis without adequate antibiotic cover is also hazardous. Infection may be introduced at operation in particular during cardiac surgery or during the introduction of catheters for investigative procedures or for prolonged intravenous infusion.

Certain types of patient are more likely to develop septicaemia; the diabetic, the patient with leucopenia, the patient in renal failure, or the patient on steroids. There is a higher incidence of septicaemia in the very young and in the patient over 60 years.

\section{Diagnosis of septic shock}

Many patients with septicaemia can be saved provided the diagnosis is made early and management is correct.

The signs of septic shock can be subdivided into early and late (Table 1). Many of these signs may be thought to be due to other factors, and consequently the diagnosis is made too late.

Septicaemia from whatever cause is frequently preceded by a period of pyrexia or rigors. In the early stages, the patient is frequently alert, restless and tachypnoeic and this progresses to a state of coma. Coma generally is an antemortem sign and portrays a very bad prognosis. On rare occasions tachypnoea due to myocardial failure may be noted; this generally arises in cases seen late, where hypo- tension has been assumed to be due to hypovolaemia and the patients have been over-infused in the presence of oliguria.

Tachycardia is always present, and in the presence of a normal central venous pressure and the absence of overt fluid loss, should raise the suspicion of early septicaemic shock.

Drugs may on occasions produce similar clinical signs. A patient (who had recently undergone surgery for perforated diverticulitis) was on an aminophylline infusion for his bronchial asthma. The tachycardia and restlessness was attributed to this drug. It was not until the infusion had been stopped for $2 \mathrm{hr}$, and the symptoms persisted, that the diagnosis of $E$. coli septicaemia was made.

Haemolysis secondary to an incompatible blood transfusion is rare and mild jaundice, in the presence of sepsis, should be considered infective until proven otherwise. The clostridial organism has a peculiar reputation for producing severe and rapid haemolysis. Rapidly increasing jaundice, in the presence of a fall in blood haptoglobin concentration and frank haemoglobinuria, should make one suspect clostridial myonecrosis. Jaundice may develop in the absence of intravascular haemolysis, this may be secondary to hepatocellular necrosis subsequent to hypoxia and hypotension or portal thrombophlebitis.

Many of these potentially septicaemic patients are subjected to a general anaesthetic for removal of 
retained products. Manipulation of the infected organ may provoke a bacteraemia. The anaesthetist may notice the patient develop central cyanosis, a tachycardia, a fall in blood pressure, or a failure to regain consciousness following the anaesthetic. These signs may be misinterpreted and the diagnosis made too late. The onset of late signs is associated with a bad prognosis, and acute renal failure invariably occurs.

It is important to realize that, after the administration of an antibiotic, endotoxin may be released from lysed organisms and trigger the haemodynamic crisis of septicaemic shock (Weil, Shubin and Biddle, 1964).

Patients with severe septicaemic shock may manifest with a coagulation anomaly. Cold cyanosed extremities may be indicative of severe impairment of peripheral blood flow associated with disseminated intravascular coagulation. Coagulation disorders are particularly common in meningococcal septicaemia and septicaemias following abortion.

\section{The management of septicaemia shock}

The management of patients with septicaemic shock requires an understanding of the pathophysiology. Such patients should therefore be treated in units experienced in their management. The pathophysiology of septicaemic shock has been discussed in great detail by many workers (Kitzmiller, 1971; Paton, 1969; Roberts and Laros, 1971; Romney et al., 1969).

It is important that a logical plan is implemented so that the initial and continuing evaluation of the patient in shock can be achieved.

\section{Evaluation of the patient}

A thorough history should be obtained, if necessary from a relative, the magnitude of blood loss and, in septic abortion, the type of intervention is critical, particularly the use of chemicals. Past history of drug allergies, renal disease, or cardiovascular disease is of import. Physical examination provides information regarding the source of infection and the severity of the shock state.

The mental state, and the state of peripheral perfusion are two valuable signs. Cold cyanosed extremities in a comatose patient are of grave import.

The measurable parameters important to the evaluation of shock are shown in Table 2.

Renal function reflects splanchnic organ blood flow. A deterioration in renal function is generally reflected in oliguria. However, oliguria may be prerenal, renal or post-renal in origin. Pre-renal oliguria can be excluded by assessment of the urine plasma $(\mathrm{u} / \mathrm{p})$ osmolality ratio. The normal plasma osmolality is $275-285 \mathrm{mmol} / \mathrm{kg} \mathrm{H}_{2} \mathrm{O}$ and the urine osmolality ranges between $550-800 \mathrm{mmol} / \mathrm{kg} \mathrm{H}_{2} \mathrm{O}$. Maximum urine osmolalities during dehydration are 800-1400 $\mathrm{mmol} / \mathrm{kg} \mathrm{H}_{2} \mathrm{O}$. In acute renal failure the urine/ plasma ratio approximates $1 \cdot 0$. This ratio is a valuable diagnostic guide to the state of renal function.

Dynamic blood volume. A central venous pressure line, with the tip placed in the right atrium, is essential for the proper management of septicaemic shock. Many of these patients have lost fluid through haemorrhage, sequestration of fluid in dilated bowel, or dilation of the peripheral vascular bed. One of the most important factors in restoration of blood pressure is to ensure that the dynamic blood volume is normal. A reliable guide can be obtained by central venous pressure (cvp) monitoring. Sequential changes in the cvp are more important than the initial reading; however, a cvp reading of less than $2 \mathrm{~cm} \mathrm{H}_{2} \mathrm{O}$ read at the mid thoracic level reflects a decreased volume of blood returning to the heart and levels higher than $16 \mathrm{~cm}$ imply cardiac failure. The cvp is used as an indicator of the ability of the cardiovascular system to handle increasing intravascular volume. When the cvp begins to rise rapidly with the administration of measured increments of fluid the limits of cardiovascular competence have been reached. Hardaway, James and Anderson (1967) found that the pulmonary artery pressure increases before the cvp when left heart failure develops. Thus if a patient develops evidence of left heart failure, is the absence of a high cvp, he should be treated accordingly regardless of the cvp. For this reason, provided the B.P. systolic pressure is $100 \mathrm{~mm}$ or above, it is wise to keep the cvp at a low normal level, 3-4 cm water especially if there is evidence of disseminated intravascular coagulation, as shown clinically and/or haematologically.

Peripheral circulation. Temperature, as measured from the medial aspect of the great toe, indicates the adequacy of peripheral perfusion. A rapidly falling toe temperature is a bad prognostic sign. If the toe temperature is less than $27^{\circ} \mathrm{C}$ and the difference between toe and ambient temperature less than $2^{\circ} \mathrm{C}$, the likelihood of death is high (Joly and Weil, 1969). A skin temperature widely divergent from the rectal also implies severe peripheral vasoconstriction. Rectal and toe temperature readings may give a serial guide as to the efficiency of peripheral vasodilator therapy (Ross, Lord Brock and AynsleyGreen, 1969).

Respiratory and metabolic status. Patients in severe septicaemic shock are invariably hypoxic; hypercapnoea is rare except as a terminal event.

Alveolar collapse due to accumulation of interstitial and intra-alveolar fluid (Ayres et al., 1970) produces diffusion limitations and unequal distribution of ventilation perfusion ratios. Observations by Mackenzie, Taylor and Flerely (1964) suggest the presence of considerable veno-arterial shunting in 
shock. Catecholamine and kinin production may produce vasoconstriction and bronchoconstriction.

A low pH associated with a metabolic acidosis is characteristic of severe septic shock. The degree of metabolic acidosis is a guide to the severity of any reduction in peripheral cellular perfusion. Endotoxaemia produces vasoconstriction which, when prolonged, leads to reduced tissue perfusion with subsequent cellular hypoxia (Roberts and Laros, 1971). As poor perfusion persists the cells resort to anaerobic metabolism with the accumulation of lactic acid.

Blood coagulation. Patients in endotoxic shock generally show evidence of intravascular coagulation. McKay (1962) concludes that man in endotoxic shock manifests the generalized Shwartzman reaction (GSR).

Other cases similar to those of McKay have been described, including a larger series of patients with fatal septic abortion (Josey et al., 1966; McCally and Vasicka, 1962). Autopsy findings justified the diagnosis of disseminated intravascular coagulation (DIC).

Clinically patients in septic shock show an oscillatory pattern of early hypercoagulability, followed by hypocoagulability associated with increased fibrinolytic activity.

It is essential to assess the coagulation parameters on admission, since poor peripheral perfusion is generally associated with hypercoagulation. This phase may pass into the phase of hypocoagulability which, in particular in the case of obstetric and surgical shock, may lead to fatal haemorrhage.

The clotting indices assessed depend upon the haematology department. Thrombocytopenia frequently occurs in the presence of septic shock and should not be used as the only indication of coagulation abnormality. In most patients the initial fall in prothrombin and thrombin times returns spontaneously to normal. Attar et al. (1966) found that patients who died in septic shock initially showed low fibrinogen levels with a gradual return to normal before death. Fibrinogen indices were elevated in all those who survived.

The clotting indices assessed at Whipps Cross Hospital are indicated in Table 2.

The number of platelets is frequently diminished in septicaemic states and when associated with a leucopenia, may be part of a generalized bone marrow depression.

Platelet depression, associated with a prolonged prothrombin time and fall in fibrinogen titre, is consistent with a consumptive coagulopathy.

\section{Treatment of septic shock}

The aims of treatment are to eradicate the source of infection, to restore an effective circulating blood volume and to attempt to correct the microcirculatory, metabolic and haematological disturbances.

The procedure adopted at Whipps Cross Hospital is as follows.

(1) Assess adequacy of ventilation. Give oxygen and, if necessary, use mechanical ventilation.

(2) Assess electrolyte and acid-base status. Insert a cvp line. Restore the circulating blood volume and if possible, correct metabolic imbalance.

(3) Take blood and other cultures and start appropriate antibiotic therapy. Give the antibiotics intravenously. Consider hyperbaric oxygen therapy.

(4) Should there be a poor response to (2) and (3), give massive doses of methylprednisolone intravenously.

(5) Should the cvp be raised consider digitalis.

(6) Should the condition remain critical consider intravenous isoprenaline.

(7) Measure the urine plasma osmolality ratio.

(8) If the urine/plasma ratio is less than $2: 1$, insert a bladder catheter and measure urine output. If less than $50 \mathrm{hr}$ have elapsed from the onset of oliguria and the urine/plasma ratio is less than $1: 1$,

TABLE 2. Parameters used in the evaluation of shock

\begin{tabular}{ll}
\hline \multicolumn{1}{c}{ Function assessed } & \multicolumn{1}{c}{ Measurable parameter } \\
\hline Renal function & $\left\{\begin{array}{l}\text { Urine volume per hour } \\
\text { U/p osmolality ratio prior to diuretic } \\
\text { therapy } \\
\text { Response to i.v. Mannitol } \\
\text { (In the presence of oliguria and a nor- } \\
\text { mal cvp) } \\
\text { Central venous pressure } \\
\text { Pulse pressure } \\
\text { Dynamic blood volume } \\
\text { Cardiac output } \\
\begin{array}{l}\text { Peripheral circulation } \\
\text { Metabolic and respiratory status } \\
\text { Blood coagulation }\end{array} \\
\begin{array}{l}\text { Blood gas analysis. pH and acid-base status } \\
\text { Fibrinogen titre }\end{array} \\
\text { Prothrombin time } \\
\text { Kaolin partial thromboplastin time } \\
\text { Platelet count }\end{array}\right.$ \\
\hline
\end{tabular}


give up to three doses of mannitol $(0 \cdot 2 \mathrm{~g} / \mathrm{kg}$ body weight) i.v. over $2-3 \mathrm{~min}$ at 2 -hourly intervals until the urine volume is at least $50 \mathrm{ml} / \mathrm{hr}$.

(9) If there is no response to mannitol, consider massive doses of frusemide.

(10) Should there be no increase in urine volume, establish the conservative regime for acute renal failure. Assess the appropriate time for dialysis. Reassess the drug dosage in the light of impaired renal function.

(11) Assess the haematological status, including evidence of intravascular haemolysis, hypercoagulation or hypocoagulation.

(12) Consider surgery.

\section{Comments}

\section{Ventilation}

Ventilator therapy is an important aspect in the treatment of the shock lung syndrome. Should the $\mathrm{PaO}_{2}$ not rise above $70 \mathrm{mmHg}$ of oxygen given via a face mask, IPPV should be considered. Intubation with mechanical ventilation has a number of important advantages.

(1) It decreases the work of and oxygen lost from breathing.

(2) It prevents sudden decreases in gas exchange due to atelectasis. Atelectasis is common in these very ill patients and is a consequence of exhaustion and inadequate ventilation.

(3) Allows sedation and adequate analgesia without producing respiratory depression. This makes management of the patient far easier.

(4) It prevents the onset of pulmonary oedema.

(5) It prevents the onset of atelectasis and subsequent infection by allowing easy access to the bronchial tree for aspiration and physiotherapy.

\section{Correction of metabolic balance and dynamic blood volume}

Many patients with poor peripheral perfusion will show a metabolic acidosis, and superimposed upon this may be a respiratory acidosis. It is important not to overcorrect the metabolic acidosis since, with restoration of the circulating blood volume, the tendency towards a metabolic acidosis will cease. Sodium bicarbonate is generally used for correction, and there is a danger of creating sodium overload. In view of these factors it is wise to correct to a base deficit of 8 on the Astrup analysis according to the formula (Measured Base deficit - 8) $\times 0.3 \times$ $\mathrm{Kg}$ body weight $=\mathrm{mEq}$ of bicarbonate ions required (Astrup, 1961).

The sodium bicarbonate should be run in over 30 min. Further Astrup analyses are performed according to the rate of patient progress, the degree of the original metabolic deficit, and the respiratory status.
Patients with a low cvp and suspected hypovolaemia, should have rapid replacement therapy with whole blood, plasma, colloid, or electrolyte solutions.

Should there be no severe blood loss or frank metabolic abnormality, Dextran 70 has proven to be an excellent blood volume expander (Gruber, 1970). Blood loss should not be replaced with blood $\overparen{\otimes}$ unless severe, since the oxygen transport capacity is highest at a haematocrit value of around $30 \%$ (Hint, 1968). Should a circulating haemolysin be. present, blood replacement should be delayed for a $\overrightarrow{\vec{\omega}}$ few hours if possible until the antibiotics have begun $\stackrel{\sigma}{\sigma}$ to take effect hyperbaric oxygen appears to eliminate $\vec{C}$ haemolysis in clostridial infections, and hyperbaric 3 . oxygen therapy should be given before blood in cases of clostridial septicaemia (Hanson et al., 1966).

Volume replacement with blood in the presence of acute renal failure and no renal dialysis can be dangerous since hyperkalaemia may develop. Dex- $\infty$ tran 70 in $5 \%$ Dextrose is the volume expander of $\frac{0}{2}$ choice unless haemoglobin depletion is sufficiently $\rightarrow$ severe to necessitate transfusion. Should this be so, $\vec{z}$ blood should be as fresh as possible and should be given preferably during dialysis.

\section{Antibiotic therapy: hyperbaric oxygen therapy}

Blood cultures and cultures from the suspecteg source of infection are essential before starting antibiotic therapy. All antibiotics should be given intravenously.

The antibiotics used depend upon the organism suspected. Should septicaemia develop following $\overrightarrow{\vec{O}}$ intra-abdominal surgery and the patient has not had 3 previous antibiotic therapy, the combination of ampicillin and a cephalosporin may be effective. It must be remembered however, that the coliform organism is frequently resistant to ampicillin and that the klebsiella organism may be resistant to $\frac{0}{3}$ cephalosporins. The combination of intravenous trimethoprim* and sulphadimidine (in a dosage of 윽 $100 \mathrm{mg}$ of trimethoprim and $500 \mathrm{mg}$ sulphadimidine) coupled with a cephalosporin is proving to be very $\frac{}{5}$ efficacious and will probably be the drug combina- $\rightarrow$ tion of choice where bacterial resistance is suspected (personal experience).

At present, where bacterial resistance to ampicillin and a cephalosporin is suspected, or where the $\mathcal{N}^{-}$ patient is thought to be suffering from gram nega- $\omega$ tive shock, a combination of gentamicin coupled with a cephalosporin should be used.

The dosage of gentamicin required to achieve a bactericidal blood level may be very variable (de- $?$ pending on renal function) and has therefore to be

\footnotetext{
* Intravenous trimethoprim is available on clinical trial from Burroughs Wellcome Company.
} 
carefully regulated according to peak and trough blood levels.

Cephaloridine should be used with care in the presence of renal failure and the dosage should be regulated according to blood levels. Cephalothin does not appear to be nephrotoxic.

Should the patient continue to deteriorate, bacteroides septicaemia must be considered and lincomycin added to the above regime.

Suspected staphylococcal septicaemia should be treated with a combination of fucidin and cloxacillin.

Pseudomonas or proteus septicaemia should be treated with a combination of carbenicillin in high dosage intravenously coupled with gentamicin.

The antibiotic combination may be altered as soon as the organisms are isolated from the blood culture and their sensitivities are available.

Hyperbaric oxygen therapy is indicated in all severe cases of clostridial infection and dramatically relieves toxaemia and septic shock (Hanson et al., 1966).

\section{Steroid therapy}

Corticosteroids have come to hold an important place in the management of septic shock. Lillehei et al. (1967) point out that physiological levels are not therapeutic and steroids must be used in massive pharmacological doses. Bolus doses of $1 \cdot 0-2 \cdot 0 \mathrm{~g}$ methylprednisolone i.v. at 3-4 hourly intervals should be given until the blood pressure has become recordable and peripheral perfusion has improved. Lillehei (1972) is now recommending methylprednisolone in doses of $30 \mathrm{mg} / \mathrm{kg}$ body weight given rapidly i.v.* The steriods can be stopped immediately, tailing off is unnecessary.

The effect of steroids is dramatic. Steroids should be used in septicaemic shock if there is a normal or raised cvp in the presence of severe hypotension, oliguria, and poor peripheral perfusion. Bolus doses of 1-2.0 $\mathrm{g}$ of hydrocortisone may induce a marked diuresis which is associated with heavy potassium loss and consequent hypokalaemia and hypovolaemia. High urinary potassium loss is less likely to arise with methyl prednisolone but a diuresis may occur. Monitoring of cvp and electrolyte balance are essential when using massive doses of steroids.

Large doses of corticosteroids given to patients in septicaemic shock result in a sustained rise in cardiac output and a decrease in peripheral vascular resistance (Samblin, Weil and Velhoji, 1965). Cortisone may also stabilize cellular membranes and lysosomes and thus protect against injury from endotoxin (Weisman and Thomas, 1962).

\section{Digitalis}

Should cardiac failure be suspected, digitalization

* $125 \mathrm{mg}$ and $500 \mathrm{mg}$ ampoules of methylprednisolone sodium succinate are now obtainable from Upjohn's Ltd. should be considered. This is particularly indicated in the patient with a sustained tachycardia. The serum potassium must be normal prior to digitalization and the dosage given should be low, since in the presence of impaired renal function there is a danger of digoxin toxicity. The initial dose, generally 0.5 $\mathrm{mg}$, should be titrated slowly intravenously, under ECG monitoring control, a further dose of 0.25 mg may be indicated over the subsequent $12 \mathrm{hr}$. Frequently, digitalis can be stopped after $48 \mathrm{hr}$ when the patient's condition has improved.

\section{Isoprenaline}

It has been shown recently that should shock persist after the use of steroids, isoprenaline is the next drug of choice (Mortsay et al., 1970). Drugs producing peripheral vascular constriction are contraindicated (Kitzmiller, 1971).

Isoprenaline is a pure beta-mimetic drug which results in arteriolar dilatation, and an increased heart rate and stroke volume leading to increased cardiac output (Hermreck and Thal, 1968). Clinically this drug has been found very valuable when steroids and volume replacement have failed. Continuous ECG monitoring is mandatory in order to detect increased ventricular excitability. Isoprenaline in a concentration of $8 \mu \mathrm{g} / \mathrm{ml}$ is infused and the drop rate regulated so that the pulse rate remains below $130 / \mathrm{min}$ (rate of infusion approximately $2-10 \mu \mathrm{g}$ ! min). Tachycardia either superventricular or ventricular can generally be reverted by stopping the infusion. A $\beta$-adrenergic blocker such as practolol may be used should the tachycardia persist. $\beta$ adrenergic blockers should be used with extreme caution in endotoxic shock since there is a danger of asystolic arrest. Practolol should be used in preference to propranolol because of its intrinsic sympathomimetic activity.

\section{Renal function}

Immediate assessment of renal function in septicaemic shock is mandatory. Patients in renal failure are predisposed to fluid overload, hyperkalaemia and drug toxicity. Patients with a urine/plasma osmolality ratio of less than $1 \cdot 1$ usually develop acute renal failure. Mannitol infusion may save patients with poor renal perfusion from developing acute renal failure.

Massive doses of frusemide are now being used in patients with oliguria. Fries et al. (1971) state that the increased diuresis obtained with intravenous frusemide facilitates dietary management especially if intravenous feeding is indicated. One has the impression that the duration of oliguria may be reduced in certain instances. We give up to $2000 \mathrm{mg}$ of frusemide intravenously daily. No side effects have been seen provided the drug is given at a rate 
of not greater than $250 \mathrm{mg} / \mathrm{hr}$. The drug should be administered in one-fifth $\mathrm{N}$ saline.

Renal dialysis has to be started early in these patients. Peritoneal dialysis is generally successful even following abdominal surgery or septic abortion. Should there be anxiety about intestinal or uterine trauma, the catheter should be inserted under direct vision. The catheter should be inserted into the iliac fossa following septic abortion or where a midline incision may have led to adhesions of the intestine to the anterior abdominal wall. Haemodialysis may be necessary where the pelvic or posterior peritoneal membrane has been broken, or the uterus considerably enlarged.

Many of these patients have intestinal atony for the first 4-5 days and intravenous feeding may be necessary.

Once acute renal failure has been diagnosed, it is essential to reassess the drugs being given, this in particular applies to the ototoxic and nephrotoxic antibiotics. The dosage of antibiotics in the presence of renal failure should be regulated according to peak antibiotic blood levels. Regulation of antibiotic dosage in the presence of continuous peritoneal dialysis can be difficult since many antibiotics appear in the dialysate. Cephalothin should be used instead of cephaloridine in the presence of renal failure.

\section{Haematological status}

A fall in platelet count and fibrinogen titre is common in septicaemic shock. Poor peripheral perfusion secondary to endotoxic shock leads to local hypoxic vessel wall damage and subsequent intravascular coagulation (Editorial, 1968). Once intravascular coagulation occurs, physiological mechanisms come into play to remove the fibrin or 'decoagulate'. Pregnant women appear to be particularly prone to episodes of disseminated intravascular coagulation leading to microcirculatory blockade (Cash, 1971). Normal pregnant women display a depression of circulating plasminogen activator in the later months of pregnancy (Bonner, McNicol and Douglas, 1969), and in some of these there is an inability to mobilize plasminogen activator in response to physiological stimuli (Woodfield, Cole and Cash, 1968).

The decision is when to use drugs preventing disseminated intravascular coagulation. Margulis et al. (1971) go so far as to suggest that intravenous heparin should be used routinely in septic abortion.

Replacement of clotting factors coupled with volume expansion, steroids and antibiotics is generally sufficient in patients with evidence of excessive bleeding, a falling fibrinogen titre, platelet count and prolonged prothrombin time. Once peripheral perfusion has improved, consumption of clotting factors generally stops.

Should peripheral perfusion remain poor in spite of these measures and there is evidence of continued consumption of clotting factors (as shown by im- $\frac{a}{c}$ provement in clotting indices following replacement therapy and a subsequent deterioration) then anticoagulation with heparin should be considered. Theo dosage of heparin must be controlled by assessment of thrombin times and should be given as a con- $-\frac{\bar{s}}{\frac{1}{\alpha}}$ tinuous infusion. The thrombin time should be $\underset{\Omega}{\mathbb{\Phi}}$ kept at approximately $1 \frac{1}{2}-2$ times normal. (There is evidence from animal experiments that better results ${ }_{-}$ are obtained if heparin is given early and in a dose? large enough to prolong the thrombin time (Flute, $\vec{\omega}$ 1972). Fibrinolysis in isolation is rare and should it be present, should be stopped with intravenous epsilon amino caproic acid. Inhibitors of fibrinolysis 3 . should not be used without simultaneous admini-ir stration of heparin and should be avoided if there isic evidence of intravascular coagulation (Merskey $e t_{\omega}^{\infty}$ al., 1967).

There have been claims that consumption co-agulopathy associated with fibrinolysis can be satis-음 factorily treated with intravenous trasylol (Kaller, 1967). The dosage used should be high, $1,000,0003$ i.u. intravenously as a slow intravenous infusion over $30 \mathrm{~min}$ followed by 50,000 i.u. hourly until $\overrightarrow{0}$ haemostasis has been achieved.

\section{Surgery}

It is imperative, at the initial clinical assessment, to consider whether there is any septic focus thato can be removed surgically. 'Medical' resuscitation may improve the patient initially but should there be an extensive nidus of infection, medical treatmentō alone will not save the patient.

Intraperitoneal leakage of bile, urine, blood or gastrointestinal contents may necessitate an emergency laparotomy. An obstructive uropathy associa-윽 ted with a pyonephrosis and septicaemia or $a_{-}^{-}$. perineptric abscess may also require urgent drainage. 3

After septic abortion a pelvic examination under. general anaesthetic is mandatory and retained pro- $\frac{}{3}$ ducts must be removed. Hysterectomy may be necessary if the uterus is gangrenous.

Many of these patients are critically ill and the time taken for resuscitation has to be carefully assessed. Should the patient be rapidly deteriorating o and it is considered that urgent surgery is manda $\mathrm{N}$ tory, it is advisable to insert a central venous pres? sure line, assess the metabolic balance, replace the ${ }^{\omega}$ dynamic blood volume and operate under cover of steroids and antibiotics. These patients are predis $-\frac{0}{\tau}$ posed to cardiac dysrhythmias and should be monitored throughout the operation. Should acute renal failure be present and the serum potassium ${ }_{0}^{-}$ be higher than $5.4 \mathrm{mEq}$ preoperatively, the operation should be covered with insulin and glucose intra- $\frac{?}{\mathbb{0}}$ venously; the anaesthetist must ensure that the 
patient does not develop a respiratory acidosis. A peritoneal dialysing catheter or arteriovenous shunt can be inserted in the theatre in preparation for renal dialysis.

It is important in these critically ill patients to have fresh frozen plasma of the correct blood group available. There is a considerable danger of bleeding due to loss of coagulation factors from consumption or replacement of massive blood loss with old blood. Three packets of fresh frozen plasma should be given after every tenth unit of blood, since loss of labile coagulation factors may lead to excessive bleeding.

\section{Conclusion}

The case histories of three patients with septicaemia have been presented. The diagnosis and pathophysiology of septic shock has been briefly discussed. The method of treatment of septic shock at Whipps Cross Hospital has been described.

\section{Addendum}

It is probable that the central venous pressure does not always reflect left ventricular function in response to various factors producing a shocked state. Initial evaluation suggests that transcutaneous aortovelography (a technique adopting the Doppler principle for assessing transaortic blood velocity) will prove to be an easy method of assessing sequentially left ventricular function. This technique may radically affect fluid and drug therapy in the management of the shocked patient (personal communication).

\section{Acknowledgments}

I am grateful to Miss D. Kayton, Consultant Obstetrician and Gynaecologist and Mr M. Hall, Consultant Urologist of Whipps Cross Hospital for allowing me to present their cases.

I wish to thank Dr W. K. Slack (Consultant Anaesthetist and Consultant in charge of the Hyperbaric Oxygen Unit, Whipps Cross Hospital) for allowing me to have access to Unit records.

I am also grateful to Mrs Selby for her secretarial assistance.

\section{References}

AstruP, P. (1961) A new approach to acid-base metabolism Clinical Chemistry, 7 (1), 1.

Attar, S.M.A., McLaughlin, J., Manskerger, A.R. \& Cowley, R.A. (1966) Prognostic significance of coagulation studies in clinical shock. Surgery Forum, 17, 8.

Ayres, S.M., Mueller, H., Giannelli, S., Fleming, P. \& GraCe, W.J. (1970) The lung in shock. American Journal of Cardiology, 26, 588.

Bernardo, A., Santamarin, G. \& Smith, Sumner, A. (1970) Septic abortion and septic shock. Clinical Obstetrics and Gynecology, 13, 291.

BonNer, J., McNicol, G.P. \& Douglas, A.S. (1969) Fibrinolytic enzyme system and pregnancy. British Medical Journal, 3, 387.
Cash, J.D. (1971) Fibrinolysis in pregnancy. Proceedings of the Royal Society of Medicine, 64, 36.

EDITORIAL (1968) Consumptive coagulopathy in septicaemic shock. New England Journal of Medicine, 279, 884.

FINLAND, M. (1970) Changing ecology of bacterial infections as related to antibacterial therapy. Journal of Infectious Diseases, 122 (No. 5), 419.

Flute, P.T. (1972) Intravascular coagulation. Postgraduate Medical Journal, 48, 346.

Fries, D., Poset, N., Dubois, N. \& Traejer, J. (1971) The use of large doses of frusemide in acute renal failure. Postgraduate Medical Journal (Suppl.), 47, 18.

GruBER, U.F. (1970) Recent developments in the investigation and treatment of hypovolaemic shock. British Journal of Hospital Medicine, 4 (No. 5), 631.

Hanson, Gillian C., Slack, W.K., Chew, H.E.R. \& Thomas, D.A. (1966) Clostridial infection of the uterus. A review, treatment with hyperbaric oxygen. Postgraduate Medical Journal, 42, 499.

Hardaway, R.M., James, P.M. JR. \& Anderson, R.W. (1967) Intensive study and treatment of shock in mac. Journal of the American Medical Association, 199, 779.

Hermreck, A.S. \& Thal, A.O. (1968) The adrenergic drugs and their use in shock therapy. Current Problems in Surgery, July.

Hint, H. (1968) Pharmacology of Dextran and the physiological background of clinical use of Rheomacrodex and Macrodex. Acta Anaesthia Belgique, 19, 119.

JoLY, H.R. \& WeIL, M.H. (1969) Temperature of the great toe as an indication of the severity of shock. Circulation, 39, 131.

Josey, W.E., Hock, W., Moon, E.C. \& Thompson, J.D. (1966) Analysis of twenty-one septic abortion deaths with special reference to the Shwartzman phenomenon. $O b$ stetrics and Gynecology, 28, 335.

Kaller, H. (1967) Pharmacology of Trasylol. Extract from new aspect of Trasylol-therapy Symposium in Bad Godesberg 1967. F.K. Schattauer-Verlag, Stuttgart: New York.

Kitzmiller, J.L. (1971) Septic shock. An eclectic view. Obstetrics and Gynecology Survey, 26, 105.

LILLEHEI, R.C. (1972) Lecture delivered at Kings College Hospital. Pathophysiology of Shock.

Lillehei, R.C., Dietzman, R.H., Mousas, S. \& Block, J.H. (1967) Treatment of septic shock. Modern Treatment, 4, 321.

McCally, M. \& Vasicka, A. (1962) Generalized Shwartzman reaction with hypofibrinogenaemia in septic abortion. Obstetrics and Gynecology, 19, 359.

MCKAY, D.G. (1962) The generalized Shwartzman reaction in the pregnant woman. Obstetrics and Gynecology, $20,446$.

McKenzie, G.J., TAylor, S.H. \& Flerely, D.C. (1964) Circulatory and respiratory studies in myocardial infarction with cardiogenic shock. Lancet, ii, 825.

Margulis, R.R., Austin, R.W., Lovell, J.R. \& RobB, H. (1971) Heparin for septic abortion and the prevention of endotoxic shock. Obstetrics and Gynecology, 37, 474.

Merskey, C., Johnson, A.J., Fleiner, G.J. \& Wahl, H. (1967) The defibrination syndrome: clinical features and laboratory diagnosis. British Journal of Haematology, 13, 528.

MORRIS, J.A. (1967) Bacteraemic shock in obstetrics. Incidence in Obstetrics and Gynaecology. Vol. 1. (Ed. by S. C. and Marcus. C.C. Marcus), Williams and Wilkins Co., Baltimore.

Mortsay, G.J., Alho, A., Jaeger, T., Rietzman, R.A. \& LILlEBEI, R.C. (1970) Effects of corticosteroids on the circulation in shock. Experimental and clinical results. Federation Proceedings, 29, 1861. 
Murdoch, J.C. McC., Speirs, C.F. \& Pullen, H. (1968) The bacteraemic shock syndrome. British Journal of Hospital Medicine, 1 (No. 3), 346.

Neely, W.A., Berry, D.W., Rushton, F.W. \& Hardy, J.D. (1971) Septic shock. Clinical physiological and pathological survey of 244 patients. Annals of Surgery, 173 (No. 5), 657.

Paton, A. (1969) Shock. Editorial. Postgraduate Medical Journal, 45

Roberts, J.M. \& LARos, R.K. (1971) Haemorrhagic and endotoxic shock: a pathophysiologic approach to diagnosis and management. American Journal of Obstetrics and Gynecology, 110, 1041.

Romney, S.L., Schulman, H., Goldman, R.M., Guercio, L.R.M. DEL \& SiEgAL, J.H. (1969) Haemodynamic evaluation of patients with puerperal sepsis and shock. American Journal of Obstetrics and Gynaecology, 105, 797.
Ross, B.A., Lord Brock \& Aynsley-Green, A. (1969) Observations on central and peripheral temperature in the understanding and management of shock. British Journal of Surgery, 56, 877.

Samblin, M.P., WeIL, M.H. \& Velhoj, V.N. (1965) Acute $\overline{\bar{F}}$ pharmacodynamic effects of glucocorticoids. Circulation, $31,523$.

Weil, M.H., Shubin, H. \& Biddle, M. (1964) Shock caused by gram-negative microorganisms. Analysis of 169 cases. Annals of Internal Medicine, 60, 384.

Weisman, G. \& Thomas, C. (1962) Studies on lysosomes 1. The effects of endotoxin, endotoxin tolerance and cortisone $\mathscr{\omega}$ on the release of acid hydrolases from a granular function $\overrightarrow{0}$ of rabbit liver. Journal of Experimental Medicine, 116, 433. Woodfield, D.G., Cole, S.K. \& CASH, J.D. (1968) Impaired fibrinolytic response to exercise stress in normal pregnancy. Oे American Journal of Obstetrics and Gynaecology, 102, 440. 